\title{
Assessing the Social Media User's Credibility Rating of Shared Content, and its Utilization in Decision Making
}

\author{
Hadiza Wada ${ }^{1 *}$ \\ ${ }^{\text {I} A s s o c i a t e ~ P r o f e s s o r, ~ D e p a r t m e n t ~ o f ~ M a s s ~ C o m m u n i c a t i o n, ~ K a d u n a ~ S t a t e ~ U n i v e r s i t y, ~ K a d u n a, ~ N i g e r i a ~}$
}

\begin{abstract}
This study seeks to ascertain the degree to which people rely on unprofessionally processed information from social media to make decisions or take critical actions. Professional media, in this case, refers to the traditional broadcast and print media who have been in the business of professionally processing and authenticating information for their audiences. While social media represent the various platforms for social exchange of information. Relevant to this study is the social media's ability to reach multitudes of people with unsubstantiated information. The methodology employed is simple random sampling, using questionnaire as an instrument. 350 respondents provided input using three age ranges, 20-35, 36-50, and 50 and above. The results show social media usage as the only news source for the youngest age group at $38 \%$. The 50 plus years mainly rely on professional media. While all three age groups admitted to sharing of unsubstantiated information at $68 \%$, only $30 \%$ admit to using critical information from social media. Most importantly, the findings indicate; where prevalence and availability tends to overwhelm users, taking the time to seek more credible information takes a back seat, even in cases where the information sought is critical to decision making and use.
\end{abstract}

\begin{tabular}{|c|c|c|c|}
\hline \multicolumn{4}{|l|}{ Keywords: } \\
\hline \multicolumn{4}{|c|}{ Social Media; } \\
\hline \multicolumn{4}{|c|}{ Traditional Media; } \\
\hline \multicolumn{4}{|c|}{ News Credibility; } \\
\hline \multicolumn{4}{|l|}{ Fake News. } \\
\hline \multicolumn{4}{|c|}{ Article History: } \\
\hline Received: & 24 & November & 2020 \\
\hline Revised: & 20 & February & 2021 \\
\hline Accepted: & 03 & March & 2021 \\
\hline Published: & 01 & April & 2021 \\
\hline
\end{tabular}

\section{Keywords:}

Social Media;

Traditional Media

News Credibility;

Fake News.

Published: $01 \quad$ April

\section{1- Introduction}

Professional media, sometimes referred to as traditional media has gradually become just a part of the general media world. Multimedia content provision is now the norm while social media practically invaded the media domain, providing information and media content to anyone willing to read, listen or watch. Soon traditional media establishments including conglomerates began to lose their audiences to internet users, while most joined the trend by operating blogs and incorporating social media into their live interactive programs. Scholars have studied various aspects of such relationships including its effect on programming content, delivery method and quality of what is served to the audience ultimately [1]. Some see positive impact [2] when radio is converged with social media for interactivity during broadcasts, while others add that social media has consistently outscored traditional media in breaking news [3]. Bosch further added that social media has changed ways in which news are generated and accessed. In Africa, Pavlik sees only the rising impact of the internet and social media, just as the tools that provide consumers with such services continue to improve and multiply in number. Most of these studies, however, seem to be interested in the unfolding trends, without necessarily studying the ways in which social media impacts the audiences' ability to readily access the authenticated but fast diminishing professional sources for their critical information needs. It becomes more dire if the general public is overwhelmed by the incredible but more popular social media sources of information as they seek to make critical life decisions, such as those relating to health and security. Data and findings from this study on the use of social media

* CONTACT: Hadiza.wada@kasu.edu.ng

DOI: http://dx.doi.org/10.28991/esj-2021-01269

(C) 2021 by the authors. Licensee ESJ, Italy. This is an open access article under the terms and conditions of the Creative Commons Attribution (CC-BY) license (https://creativecommons.org/licenses/by/4.0/). 
to make life and death, including security decisions is at $30 \%$. That is very significant. The study's relevance includes its contribution to present day body of knowledge on media choice (Selective exposure), selective perception, i.e. perception of message credibility and uses, as well as information sharing and use.

The paper starts with statement of the problem to be addressed, followed by the theoretical framework for analysis of findings. That framework, users and gratification theory, aims to aid in placing the issue in proper perspective for social scientific analysis. A presentation of similar studies related to the paper's topic follows under the subtitle, 'Related Literature' where two subtopics of studies on the impact of both professional and social media, and those relating to issues of credibility of social media, or lack thereof are presented. The survey results are presented last, along with discussions and analyses, followed by the conclusion subtitle.

\section{1-1- Statement of the Problem}

The prevalence of social media platforms and increasing usage trend, in addition to its circulation of unverified but at times critical information is a major concern, most especially when the issue circulated borders on political stability, security, health and other matters of life and death. Scholarly articles have been written on the uses of social media in recent years for social marketing and mobilization [4], most especially after the Arab Spring or mass demonstrations the world saw in several countries of the Middle East and North Africa, from Tunisia to Egypt's Tahrir Square between 2010 to 2012.

Then there is the challenge among social media users in discerning which piece of information is credible and which is not. Most users do not have ways of assessing the credibility of information [5]. More often than not, the source of the information is not indicated for the user, especially in the case of information shared repeatedly via a chain of networks through the social media. The potential for intentional misuse of social media to spread misinformation, rumors and even fake news is also a concern. Fake news [6] is defined as 'deliberate misinformation spread through traditional or online media,' with the word fabricated featuring in most definitions. Among the questions this study attempts to answer therefore, is the audiences' rating of social media contents and how reliable they think it is as far as being a source of news and information. Do they think what they get via social media is reliable? Would they act or react to messages on social media? Have they actually acted on any information they have previously received from social media?

\section{2- Theoretical Framework}

Uses and Gratification theory has contributed a lot to our understanding of how media contributes its quota in the lives of those that use it, i.e., its audience. Research categorized under this theory has continued to enrich our understanding of the choice and utilization of media content by the general audience. In 1969, Jay Blumler and Denis McQuail studied the United Kingdom 1964 election and categorized people's motives for watching certain political programs on television [7]. These audience motivations formed the foundation for their research in 1972 and led to active audience theories, better known later as Uses and Gratification Theory, UGT. The theory stresses the basic premise that audiences are not passive consumers of media content. The selectivity aspect as a branch of active listener's theory helps us analyze what audiences seek from the media, and for what reason they seek it; selective exposure. How they choose (select) content, including their psychological processing of that choice probed under selective perception, and what they seek to process and retain mentally, selective retention. And finally how they store such information mentally and use it in their lives whenever the opportunity for application arises.

\section{3- Literature Review}

\section{3-1- General Impact of New Media on Professional Media}

With the introduction of new media and the resultant proliferation of news sources far beyond the traditional media, many studies were conducted to find out how the new media impact traditional media. A number of studies foresee the culture of passive audiences or 'sit back and be told' fast diminishing, as audience involvement became the norm [8]. Others however admit that the abundance of social tools for creating media content by unprofessional users (amateurs) is posing serious threats to traditional media's existence and influence [9]. Others see new media as a positive means of contributing to the discourse, as a shift from industrial production of content towards a more collaborative engagement of communities of participants positively impacts traditional media production value chain [10]. New media tends to extend the reach of traditional media to specialized audiences [11], seeing the high involvement of the younger generation in conventional media activities is via social media, citing a study that shows otherwise more than $60 \%$ of younger Americans are moving away from traditional delivery systems altogether.

Zhang (2012) [12] see the prevalent use of new media posing a threat to conventional media, while Ogedi (2009) [13] pointed at the issue of authenticating new media information incorporated into traditional media programming without compromising professional standards as a current challenge. Apart from operating blogs, it has been reported [14] that $60 \%$ of European public radio have Facebook accounts and 53\% have twitter. 
More recent studies seem to have shifted to in-depth matters and concerns, such as seeking actionable information [15], as well as a growing habit of using new media for most occupational and social needs including usage in relating to parents and peers by the younger generation [16]. Boulianne (2017) examined the effects of social media use on political participation and found that political expression uses far exceeds uses for informational purposes. Kircaburun et al. (2018) [17] measured five personality traits in correlation with social media platform motives for use. The findings suggest "preferences of social media use differ according to the users' individual differences and user motives; and that these factors can lead to problematic social media use (PSMU) among minority of users." As for addiction to social media use, [18] a 2018 study examined, personality, self-liking, and daily internet use regarding the use of Instagram and discovered that " $66.5 \%$ of the participants were not addicted, $26.5 \%$ were mildly addicted, 6.1 moderately addicted and $0.9 \%$ severely addicted."

In their unpublished conference paper, of more direct relevance to this study titled 'Reliance, Media Exposure and Credibility' [19], the authors examined the respondents' credibility rating of both traditional and social media. Television was rated the highest in terms of media credibility while twitter was rated lowest. Upwards of 4000 respondents were surveyed before the general elections in Malaysia in 2018 and again after the elections, in 2019. In general, "Malaysians perceived the traditional media, including TV, radio, and newspapers, as more credible than the new media (internet, online news portals, Facebook, and Twitter).” Another perception study [20], using 375 participants from different higher institutions of study in Pakistan found similar results. Television news was considered the most credible medium for political news, while street and online newspapers come second. A similar but more detailed study repeated in 2020 [21] disclosed believability, fairness, accuracy and depth of information as areas where television excels. It however found that significance of new media continues to increase, despite serious concerns expressed as to credibility "due to factors such as anonymity and absence of concrete regulator control on posting and sharing of political news and related content."

\section{3-2- Social Media and Credibility}

Social media has pervaded the life of a great majority of people across nations. From initially being accessed on desktop computers to laptops only, increased portability in the means of accessing and sharing information after it was introduced into smartphone and other mobile devices, made social media an everyday tool for not only socializing, but accessing and sharing information far and wide. As far as a means of accessing news, Wakefield (2016) [22] confirmed that $51 \%$ of people rely on social media as a news source. Tandoc (2018) [23] discovered that while 'participants rated news from a news organization as more credible than those shared on Facebook, which occurs only when motivation is high. Tandoc concluded that 'there is no significant differences in credibility rating when motivation is low.' A relevant finding from a study Askew in 2018 as cited earlier, shows how respondents admit to sharing information whose credibility they could not ascertain. Askew discovered that 'most people who shared what was happening on social media never stopped to check the facts.' In an interesting study [24] experimenting on recall ability of respondents over perceptions of credibility, the authors found that 'at time of exposure, subjects discounted material from 'untrustworthy' sources. In time, however, the subjects tended to dissociate the content from the source with the result that the original scepticism faded and the untrustworthy material was accepted.' And it added that 'lies, in fact, seemed to be remembered better than truths.'. A study, earlier cited in this work, about social media and news credibility conducted in Nigeria indicated that up to $68 \%$ of its respondents believe 'social media information is credible, while only $29 \%$ do not hold that belief.

\section{4- Results and Discussions}

A random survey of 350 respondents was conducted via the use of questionnaires. The aim was to find out the degree to which people rely on unprofessionally processed information in (i) making vital decisions or (ii) acting on unsubstantiated information served via social media. In addition, it measured the audiences' ability to differentiate information emanating from professional, versus social media.

The data was categorized variously, in ways that indicate significant information based on the studies focus. For example, it was discovered that while a higher percentage of younger people among the respondents (20-35 years) rely on social media as the only source of news than their older counterparts who supplement social media information with other news sources, the measurement for the perception of news credibility does not show much difference between ages.

There were three age ranges used, 20-35 (42\% of respondents), 36-50 (35\% of respondents), and 50 and above (23\% of respondents). The frequency of usage of social media varies significantly by age range also with $60 \%$ of $20-35$ admitting frequent use (several times a day) and $23 \%$ as occasional daily users. The more mature users $36-50$ years have $44 \%$ of its respondents at the several times a day level and $31 \%$ occasionally. 
Among younger users 20-35 years, $38 \%$ say social media is their only daily source of news, while the rest say in addition to social media they listen to, or watch other sources of news. The significant difference comes with those 50 years and above who also use social media occasionally (23\% of respondents of that age) including for information. For that group, the main source of news, however, remain conventional media. A significant number of the age group visit blog sites, in addition to social media for other sources of news.

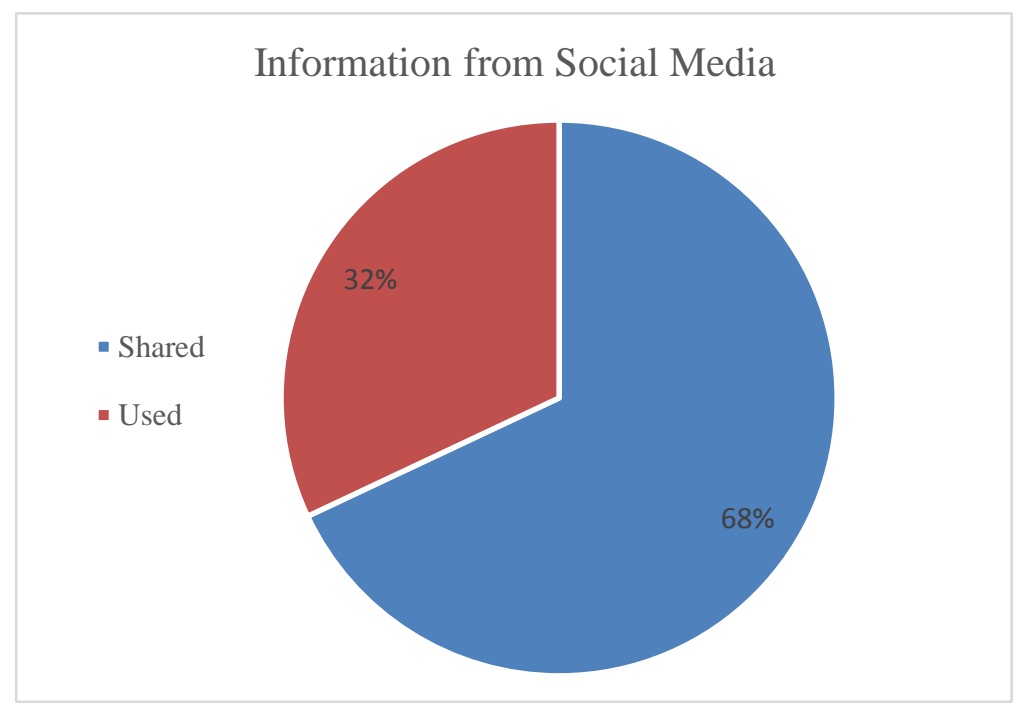

Figure 1. Those who shared versus those who actually used/acted on social media information.

On issues of perception of credibility, all three age groups admit that they hardly check the source of information retrieved from social media, and cannot ascertain credibility. They also admit that they 'sometimes' doubt the credibility of news from social media. But all three age groups participate in sharing (forwarding) information that they admit not being able to vouch for its credibility. For $68 \%$ of them, sharing unsubstantiated news is the limit. When it comes to using or acting on the information more than $30 \%$ of the respondents admit to using health advice from social media (mostly WhatsApp groups), to forwarding and further spreading critical news and information that impacts security, political stability, etc.

On the issue of measuring the audiences' ability to differentiate information emanating from professional, versus social media, a significant percentage of the respondents do know what professional media are, while some say they even try to see whether the information comes from sources they could trust. However, whether it is the inability to discern the sources of new media content, or sheer lack of motivation to check, users are willing to use and share such information even when they cannot ascertain its credibility. A pervious study already cited at the introduction section did conclude that 'most people who shared what was happening on social media never stopped to check the facts.' It is therefore plausible to infer from the results that the sheer volume of information out there, as well as user habits formed add to user's lack of motivation to check out source credibility. User habits continue to shape what is absorbed, used and/or shared, according to some studies. For example, a study of the millennials technology use habits [25] categorized them into five groups; technology devotees, technology spectators, circumspects, technology adverse users, and productivity enhancers.

The issues regarding social media use in comparison to professional media are many, some of which are enumerated on Table 1, below.

Table 1. Traditional Media versus Social Media News.

\begin{tabular}{cll}
\hline No. & \multicolumn{1}{c}{ Traditional } & \multicolumn{1}{c}{ Social } \\
\hline 1. & $\begin{array}{l}\text { Original source of information is identified with quotation marks (print), } \\
\text { sound bites (radio), and pictures (television) for proof of source. }\end{array}$ & Source of information often not readily available/stated. \\
2. & $\begin{array}{l}\text { Media entity responsible for news items identify with their news products } \\
\text { (via logo, watermark, etc.). }\end{array}$ & Original source, owner or writer not always disclosed. \\
3. $\quad$ Information is professionally processed using journalistic standards. & $\begin{array}{l}\text { Most peddlers of 'news' or information via social media are } \\
\text { amateurs, not professional journalists. } \\
\text { 4. }\end{array} \quad \begin{array}{l}\text { News may be professionally discussed by relevant professionals (Doctors, } \\
\text { Engineers, Lawyers, etc.) to assist the public in forming credible opinion. }\end{array}$ & $\begin{array}{l}\text { The circle that discusses the information are not necessarily } \\
\text { profesionals. }\end{array}$ \\
\hline
\end{tabular}


The effectiveness of social media in social mobilization and marketing [26] has already been established and demonstrated in history [27] mainly by the Arab Spring. In the mass revolts, the world witnessed people spontaneously mobilized for protest through the messages they shared amongst themselves on social media platforms. With that in mind, the implications for attaching credibility to non-credible news should be of concern to any nation. Misleading security information can cause panic and consequently chaos; misleading health information can cause disease and death, misleading social information can cause upheavals; misleading economic information can cause misjudgements in investment decisions, buying, spending etc. Credibility and authentication of any news disseminated to or shared with multitudes of people is a critical issue. Shifting values to the prevalence or popularity of a medium as argued by some scholars [28] should not equate credibility. Credibility as a term, as defined by the oxford dictionary evokes synonyms such as trustworthiness, reliability, believability and integrity.

Furthermore, in addition to the news and information being professionally processed, then provided to the public by the traditional media, these entities also engage in what is generally categorized in programming as current affairs; an expanded discussion of current news by experts. In a study [29], Facebook as a source is cited as restricting the acquisition of current affairs knowledge, depriving users of learning more about news. In short, the professional media does not just inform the public about what is happening around them, they usually provide a forum of credentialed members of the affected community to discuss important events as they occur.

So, while most studies cited in this work, such as those from Arabi, Bhutta and, Tandoc, all sought credibility rating by users, this study sought credibility rating by users, but cited other source credibility based works, as well as inferred professional media source credibility by providing a visual presentation of factual reasons as to why (Table 1) traditional sources are adjudged as more credible and reliable as well. And most of the previous studies findings also indicated reciprocation, where respondents rated the credibility of traditional media higher, most especially television news.

The Hovland and Weiss study, which was actually an experiment for information recall capabilities of subjects exposed to information, which registered degradation of the relevance of information credibility with time passage because of the disassociation of the news content and it source looms large on this study. As expressed in the introduction, one major concern is "the general public is overwhelmed by the incredible but more popular social media sources of information as they seek to make critical life decisions." This study did not explore the question of information recall as Hovland and Weiss did. It therefore recommends that more recent and contemporary studies along the lines of that which was conducted by Hovland and Weiss are needed to measure the impact of time lapse on the relevance of information source credibility.

\section{5- Conclusion}

This study exhibits the various habits of social media users regarding uses and gratification they receive from social media, most especially those related to news and information. It indicates the increasing shift from conventional to social media for the younger aged Nigerians. Also, that a significant number of younger Nigerians tend to source their news from social media only, while the older generation supplement those readily available sources with other sources of news they choose to explore from the professional media. The results, however, tend to confirm the fears of this author that most users of social media may not necessarily take the time to confirm the credibility or authenticity of a news item before they use, share, or act on it.

Results from this survey should also add to our body of knowledge and understanding of the factors that affect media choice and use, under the selective exposure and selective perception theories. This study's findings indicate that where prevalence and availability tends to overwhelm users, taking the time to seek more credible and usable information takes a back seat, even in cases where the information sought is critical to decision making and use.

As for external influences on the study, the author neither solicited nor received any funding for this research. As such, conflict of interest perceived or actual should not be a factor that may affect outcomes of the study. The author's natural interest in the subject matter was the major drive for the work, i.e. the effect of rapid technological changes and new media on professional media practice. Other authors did not contribute to any aspect of the work. All citations and references to other works, in terms of previous literature analyzed, have been fully acknowledged by way of references.

\section{6- Declarations}

\section{6-1-Data Availability Statement}

The data presented in this study are available on request from the corresponding author.

\section{6-2-Funding}

The author received no financial support for the research, authorship, and/or publication of this article. 


\section{6-3- Conflicts of Interest}

The author declares that there is no conflict of interests regarding the publication of this manuscript. In addition, the ethical issues, including plagiarism, informed consent, misconduct, data fabrication and/or falsification, double publication and/or submission, and redundancies have been completely observed by the authors.

\section{7- References}

[1] Girard, Bruce. "The One to Watch: Radio, New ICTS, and Interactivity." (Rome: Food and Agricultural Organization of the United Nations, 2003).

[2] Pavlik, John V. “Journalism and new media.” Columbia University Press, New York, (2001).

[3] Bosch, Tanja. "Social Media and Community Radio Journalism in South Africa." Digital Journalism 2, no. 1 (November 13 , 2013): 29-43. doi:10.1080/21670811.2013.850199.

[4] Brown, Guskin, and Amy Mitchel. "The Role of Social Media in the Arab Uprisings." Journalism and Media, (November 12, 2012).

[5] Edogor, Ignatius Obi, Alice Aladi Jonah, and Lucky Idowu Ojo. "Nigerian users' evaluation of credibility of social media sites." New Media and Communication Journal 4, no. 2 (2015): 69-77.

[6] Askew, Lauren. “Can We Trust Social Media as a News Source?” Miappi, (March 1, 2018).

[7] Blumler, Jay G., and Denis McQuail. “Television in politics: Its uses and influence.” University of Chicago Press, (1969).

[8] Gauntlett, David. Marketing is Connectivity. (Cambridge: Polity Press, 2011).

[9] Hendy, David. Public Service Broadcasting. New York: Palgrave-McMillan, (2013).

[10] Bruns, Axel. "The future is user-led: The path towards widespread produsage." In Proceedings of perthDAC 2007: The 7th International Digital Arts and Culture Conference, Curtin University of Technology, (2007): 68-77.

[11] Uzorchuku, Chioma. "Online Newspaper and the Future of Print Media in Nigeria." Unpublished Master's Thesis, Bayero University, Nigeria, (2018).

[12] Zhang, Sheng. "The Convergence of Conventional Media and New Technology in the Cases of New York Times and National Broadcasting Company (NBC).” Master's Thesis, Southeast Missouri State University, Carbondale, (2012).

[13] Ogedi, Nyekwere. "Influence of New Media Technology on Broadcasting: A study of television stations in Port Harcourt metropolis." Master's Thesis, University of Nigeria, Nsukka, (2009).

[14] Public Radio and New Media Platforms. Ginevra: EBU Press, (2011).

[15] Boulianne, Shelley. "Revolution in the Making? Social Media Effects across the Globe." Information, Communication \& Society 22, no. 1 (July 20, 2017): 39-54. doi:10.1080/1369118x.2017.1353641.

[16] Akram, W., and R. Kumar. "A Study on Positive and Negative Effects of Social Media on Society." International Journal of Computer Sciences and Engineering 5, no. 10 (October 30, 2017): 351-354. doi:10.26438/ijcse/v5i10.351354.

[17] Kircaburun, Kagan, Saleem Alhabash, Şule Betül Tosuntaş, and Mark D. Griffiths. "Uses and Gratifications of Problematic Social Media Use Among University Students: a Simultaneous Examination of the Big Five of Personality Traits, Social Media Platforms, and Social Media Use Motives.” International Journal of Mental Health and Addiction 18, no. 3 (May 15, 2018): 525-547. doi:10.1007/s11469-018-9940-6.

[18] Kircaburun, Kagan, and Mark D. Griffiths. "Instagram Addiction and the Big Five of Personality: The Mediating Role of SelfLiking.” Journal of Behavioral Addictions 7, no. 1 (March 2018): 158-170. doi:10.1556/2006.7.2018.15.

[19] Arabi, Syed, Shahrul Nazmi Sannusi, \& Mohammed Fadel Aranda. "Reliance, Media Exposure and Credibility.", International Conference on Media and Communication, Malaysia, (2019).

[20] Bhutta, Muhammad Makkey. "Perception of Pakistani University Students about Credibility of Political News: An [19] Analysis of Mainstream and New Media." International Journal of Biology, Pharmacy and Allied Sciences, November 6, no. 11 (2017): $2120-2138$

[21] Bhutta, Muhammad Makkey, Manan Khan Tareen, Hannan Khan Tareen. "Mapping Credibility Scale of Sources of Political News Stories Through Perception Lenses of Pakistani Youth: Analysis of Governmental vs. Non-Governmental and Conflicting Political News Sources." Journal of Peace, Development and Communication 4, no. 2 (2020): 315-334, Accessed January 16, 2021. https://doi.org/10.36968/JPDC-V04-I02-17.

[22] Wakefield, Jane. "Social Media Outstrips TV as News Source for Young People.” BBC, (June 12, 2016).

[23] Tandoc, Edson. “Tell Me Who Your Source Is: Perceptions of News Credibility on Social Media.” Journalism Practice, (January $12,2018)$. 
[24] Hovland, Carl I., and Walter Weiss. "The influence of source credibility on communication effectiveness." Public opinion quarterly 15, no. 4 (1951): 635-650.

[25] Calvo-Porral, Cristina, Rogelio Pesqueira-Sanchez, and Andrés Faiña Medín. "A Clustered-Based Categorization of Millennials in Their Technology Behavior.” International Journal of Human-Computer Interaction 35, no. 3 (March 22, 2018): $231-239$. doi:10.1080/10447318.2018.1451429.

[26] Rogers, Todd, Noah J. Goldstein, and Craig R. Fox. "Social Mobilization.” Annual Review of Psychology 69, no. 1 (January 4, 2018): 357-381. doi:10.1146/annurev-psych-122414-033718.

[27] Eltantawy, Nahed, and Julie B. Wiest. "The Arab spring| Social media in the Egyptian revolution: reconsidering resource mobilization theory." International journal of communication 5 (2011): 18.

[28] Kang, Minjeong. "Measuring social media credibility: A study on a measure of blog credibility." Institute for Public Relations (2010): 59-68.

[29] Boukes, Mark. "Social Network Sites and Acquiring Current Affairs Knowledge: The Impact of Twitter and Facebook Usage on Learning about the News." Journal of Information Technology \& Politics 16, no. 1 (January 2, 2019 ): 36-51. doi:10.1080/19331681.2019.1572568. 


\section{Appendix I: Questionnaire on Professional and Social Media Credibility Issues}

Instructions: This study is for academic purposes only, and responses will be treated with utmost confidentiality. Please respond to the following research questions by choosing the best response that corresponds to your preference, for the yes or no questions. And circle the responses that apply to you best, among the listed choices for other questions.

\section{Section A: Demographics}

$\begin{array}{lll}\text { 1. Your age range is: (a) } 20-35 & \text { (b) } 36-50 & \text { (c) } 50 \text { and above }\end{array}$

2. (i) Educational level completed: (a) Primary (b) Secondary (c) University (d) Postgraduate study

3. (ii) Gender: Male [ ] Female [ ].

\section{Section B:}

Clarification: For the sake of this study, professional media are those media entities that are in the business of professionally seeking, verifying and writing news stories, while following specified methods of vetting the stories' source, and disclosing for its audience where they got the news, from who, when it happened and how it happened, in addition to what happened. (e.g. Newspapers, Television, and Radio news). Social media on the other hand represent the various platforms for social exchange of information between friends, family and acquaintances, (e.g. Facebook, WhatsApp, Instagram, etc.).

4. Where do you get information or news from?
(a) Internet (laptop, desktop)
(b) phone
(c) browser (opera, yahoo, etc.)
(d) professional news sources (TV, Radio, Newspapers, including online) e) Other

5. What is our most favored source for news:

Prof Media [ ] Social Media [ ] Combination [ ]

6. Do you use the social media?

Yes [ ] No [ ].

7. How often do you use it?

(a) many times a day

(b) few times daily

(c) once a day

(d) rarely.

8. Do you use it for news?

Yes [ ] No [ ]

9. What professional entity or social media platform do you mostly use; you may cite more than one
10. How often do you use it for news?
(a) several times a day
(b) once a day
(c) few times a week
(d) rarely

11. As a news consumer, before now, have you been able to differentiate between news from professional media and those from Social media?

Yes [ ] No [ ]

12. Do you always know the true origin (source) of information you receive via social media? Yes [ ] No [ ]

13. Can you always ascertain the credibility (reliability) of information from social media? Yes [ ] No [ ]

14. Do you take the time to check the credibility of information or news from social media? Yes [ ] No [ ]

15. Do you take the time to check the credibility of information when its critical; e.g. when it concerns issues of health, security of life and property, political/social stability issues?

Yes [ ] No [ ]

16. If the answer to question 14 above is yes, how often do you check?
(a) All the time
(b) most of the time
(c) sometimes
(d) rarely or not at all.

17. Have you received any critical information (advice) concerning issues of health, security of life and property, political/social stability via social media?

\section{Yes [ ] No [ ]}

18. Have you shared any critical information (advice) concerning issues of health, security of life and property, political/social stability via social media before?

Yes [ ] No [ ]

19. How often have you shared such critical information?
(a) All the time
(b) most of the time
(c) sometimes
(d) rarely or not at all.

20. Have you personally used (apply) any critical information (advice) concerning issues of health, security of life and property, political/social stability received via social media? Yes [ ] No [ ]

20. If the answer to question 19 above is yes, how often do you check credibility before use?
(a) All the time
(b) most of the time
(c) sometimes
(d) rarely or not at all. 
21. How often have you used such critical information?
(a) All the time
(b) most of the time
(c) sometimes
(d) rarely or not at all.

22. How often do you receive breaking news from Social Media?
(a) All the time
(b) most of the time
(c) sometimes
(d) rarely or not at all.

23. How often do you receive breaking news from Professional Media?
(a) All the time
(b) most of the time
(c) sometimes
(d) rarely or not at all.

Thanks for your time, it's really appreciated. 